\title{
A importância do pai no pré-natal
}

\author{
The importance of the father in prenatal care \\ La importancia del padre en la atención prenatal
}

Recebido: 19/10/2021 | Revisado: 15/10/2021 | Aceito: 26/10/2021 | Publicado: 29/10/2021

\author{
Jhonata Henrique Miranda Freitas \\ ORCID: https://orcid.org/0000-0002-0144-1161 \\ Faculdade Integrada Carajás, Brasil \\ E-mail: jhonatahenriquemiranda123@gmail.com \\ Larissa Luz Alves \\ ORCID: https://orcid.org/0000-0002-8688-856X \\ Faculdade Integrada Carajás, Brasil \\ E-mail: laryluzz@hotmail.com
}

\begin{abstract}
Resumo
A presença do pai é de suma importância durante todo o ciclo gravídico, e esse trabalho tem como intuito trazer mais informações para a figura paterna sobre os seus direitos, que sua participação é fundamental durante todo o pré-natal, e os profissionais de saúde tem um papel de orientar da melhor forma e tirar todo tipo de dúvidas do pai sobre a gestação, sabemos que muitos colocam dificuldades para acompanhar as consultas de sua parceira, e um dos maiores fatores como desculpas é que muitos são o único provedor da casa e não pode se ausentar do trabalho para acompanhar as consultas de pré-natal, é neste momento que entendemos que é de extrema importância que o pai acompanhe toda a gravidez de sua parceira, pois é aonde começa o primeiro vínculo de pai e filho e também aumenta o vínculo familiar, além disso será prestado um cuidado com a saúde da figura paterna.
\end{abstract}

Palavras-chave: Participação do pai no pré-natal; Saúde do homem; Falta de conhecimento dos seus direitos.

\begin{abstract}
The father's presence is of paramount importance throughout the pregnancy cycle, and this work aims to bring more information to the father figure about their rights, that their participation is essential throughout the prenatal period, and health professionals have a role of providing the best guidance and answering all kinds of doubts the father has about the pregnancy, we know that many pose difficulties to monitor their partner's appointments, and one of the biggest factors as excuses is that many are the only provider in the house and not can be absent from work to follow prenatal consultations, this is when we understand that it is extremely important for the father to monitor the entire pregnancy of his partner, as this is where the first bond between father and son begins and also increases the family bond, in addition care will be provided for the health of the father figure.
\end{abstract}

Keywords: Father's participation in prenatal care; Men's Health; Lack of knowledge of your rights.

\section{Resumen}

La presencia del padre es de suma importancia durante todo el ciclo del embarazo, y este trabajo tiene como objetivo acercar más información a la figura paterna sobre sus derechos, que su participación es fundamental durante todo el período prenatal, y que los profesionales de la salud tienen el rol de brindar la mejor orientación y respondiendo a todo tipo de dudas que tiene el padre sobre el embarazo, sabemos que a muchas personas les cuesta dar seguimiento a las citas de su pareja, y uno de los mayores factores como excusas es que muchos son el único proveedor en la casa y no pueden ser ausente del trabajo para seguir las consultas prenatales, es aquí cuando entendemos que es sumamente importante que el padre controle todo el embarazo de su pareja, ya que es aquí donde comienza el primer vínculo entre padre e hijo y también aumenta el vínculo familiar, en Además se prestará atención a la salud de la figura paterna.

Palabras clave: Participación del padre en el cuidado prenatal; Salud de los hombres; Falta de conocimiento de sus derechos.

\section{Introdução}

Sabemos que o pré-natal deverá dar início quando a figura materna tem a confirmação que está gestante, aonde a mesma deve procurar a unidade de saúde mais próxima de sua residência, para dar início ao acompanhamento das consultas de pré-natal, aonde terá algumas avaliações pelo médico e pelo enfermeiro, sendo que a primeira consulta é realizada pelo o enfermeiro, e será feito alguns questionamentos e atualizado o cartão de vacina e também será solicitado alguns exames. 
Trabalho tem como intuito, apresentar sobre a importância do pai no pré-natal, para que eles possam entender que sua participação é de suma importância, muitos não participam desse processo, que ocorre diversas mudanças no corpo da sua parceira, e no pré-natal é onde o parceiro vai entender que as mudanças que estão acontecendo são normais, e possa compreender que seu apoio é muito importante durante toda a gestação, ele também é preparado psicologicamente para a chegada de uma criança pelo profissional adequado, sendo que a primeira consulta é de responsabilidade da enfermagem.

Muitos pais colocam muitas dificuldades para não acompanhar a gestação de sua companheira, e a enfermagem tem como papel orientar da melhor formar possível para que o pai esteja presente em todas as consultas de pré-natal, tentando articular horários mais flexíveis para o pai e para a mãe da criança.

Sabemos que nas consultas é aonde começa o primeiro vínculo de pai para filho e aumenta o vínculo familiar, e também é realizado alguns exames de rotina para cuidar da saúde do pai e poder tirar quaisquer tipos de dúvidas do que podem ocorrer durante toda a gestação.

Qual é a maior dificuldade do pai para acompanhar as consultas de pré-natal? Umas das maiores dificuldades são os horários de expediente, pois, o parceiro na grande maioria é o único provedor financeiro da casa, e nesse momento a enfermagem tem como principal função auxiliar e organizar um horário mais flexível para que o pai possa participar de toda a gestação, e possa entender que sua participação é muito importante e faz toda a diferença durante a gestação, isso inclui também os parceiros que não tem união estável.

E depois de nove meses é chegado o grande momento, O parto. Neste caso a gestante e seu companheiro tem uma grande decisão a tomar, qual o método mais indicado para ter o seu bebê. Iremos abordar os dois tipos de parto que existe, o parto normal e a cesárea. Sem sombra de dúvidas o mais indicado é o parto normal, mas infelizmente é o que menos ocorre, o porquê será explicado logo mais a frente. Logo após o nascimento os pais tem outro desafio pela frente, os cuidados com o RN são delicados e toda ajuda é bem vinda nesse momento a família tem o papel de orientar e acolher a chegada do novo membro da família.

Enfim, depois de todas essas mudanças temos a real certeza que a presença do pai faz toda a diferença, pois se ele estiver acompanhando todo esse processo, ele entenderá que a mãe necessita de total apoio e força para passar por essa fase que é tão especial para ambos.

\section{Metodologia}

\subsection{Tipo de estudo}

Trata-se de uma revisão exploratória, descritiva, da importância do pai no pré-natal. Tendo com suporte metodológico ao presente estudo, Brasil. (2019), que discorre sobre a caderneta da gestante, onde a busca foi realizada no Google acadêmico no formato de artigo acadêmico com os seguintes descritores e operadores: "A Importância do Pai nas Consultas de Pré-natal".

\subsection{Coletas de dados}

A busca foi realizada através de base de dados eletrônicos, como Scientific Eletronic Library Online (Sciello), Google Acadêmico, Ministério da Saúde do Brasil, Diário Oficial da União e a Política Nacional de Atenção Integral à Saúde do Homem.

\subsection{Critérios de inclusão e exclusão dos artigos}

Os critérios de inclusão foram basicamente: em artigo original contendo para melhor entendimento e veracidade dos fatos apresentados, no idioma português: publicados desde 2003, que foi apresentado uma relevância significativa para o embasamento da teoria até as publicações do ano de 2020, que se fazem mais atuas. Os critérios de exclusão foram de artigos que não tinham compatibilidade com a temática do artigo. 
Após realizar a pré-leitura dos artigos filtrados e selecionados com base nos critérios de inclusão e seleção, restaram 11 (onze) artigos que subsidiam a presente pesquisa. A busca teve início no mês de março de 2021, tendo inicialmente 25 artigos foram escolhidos e através de um critério próprio de inclusão e exclusão restaram 11artigos acadêmicos.

\section{Resultados e Discussão}

\subsection{Gestação}

Segundo Silva, et al. (2015). A gestação é um processo em que a mulher fica durante nove meses gerando um ser que surgiu durante um encontro de células sexuais (espermatozoide e óvulo) no momento da fecundação das duas células começa várias mudanças no corpo da mulher.

De acordo com o ministério da saúde (Brasil,2018). Toda mulher tem direito a ser atendida durante sua gestação, no parto até o pós-parto e conta com a rede cegonha, que fortalece o direito da mulher e da criança.

Nos três primeiros meses a mulher já começa a sentir as mudanças em seu corpo, os seios começam a crescer, a mulher pode passar a sentir mais fome e sono, enjoos e até mesmo cansaço. No final do terceiro mês já se pode ouvir os batimentos do bebê durante a consulta. Do quarto ao sexto mês a mãe já começa a sentir os primeiros movimentos de seu filho, isso faz com que um sentimento de alegria encha o seu coração, porém o seu corpo vai estar se desenvolvendo mais rápido e isso pode lhe trazer alguns desconfortos. Do sétimo ao nono mês tanto a mãe como o bebê já está se preparando para o parto, o bebê fica a cada dia com menos espaço e a mãe com mais cansaço e desconforto, além de sentir pouco sono. Ele já está formado, mas ainda não está maduro, espere o momento certo, pois antecipar o parto pode ser prejudicial tanto para a mãe como para o bebê. (Brasil,2018).

\subsection{Pré-natal}

Para a escola Anna Nery, a assistência do pré-natal consisti com ações destinada para a mulher durante o período gestacional puerperal, contribuindo para o desenvolvimento da gestação mais saudável, com isso reduzindo a mortalidade materna e fetal, o cartão e a caderneta da gestante é um instrumento fundamental pois contem registro da condição da saúde da mãe e do feto. (Camargos, et al. 2021).

O cartão de pré-natal foi criado no brasil, em 1988, com o intuito de facilitar e armazenar informação e diagnostico entre os profissionais que atuavam na assistência do pré-natal e os que realizavam os partos nas maternidades.

Durante a realização do cuidado gestacional, as informações registradas na caderneta podem fundamentar a tomada de decisões durante a gestação, parto, pós-parto, e até mesmo nas próximas gestações. As informações permitem ainda uma avaliação longitudinal da gestação e sua evolução quanto aos parâmetros clínicos, como altura uterina, ganho de peso, pressão arterial, edema, dentre outros. (Camargos, et al. 2021).

O pré-natal deve começar assim que a mulher descobre que está grávida. No Brasil, o Ministério da Saúde recomenda que sejam realizadas no mínimo seis consultas (uma no primeiro trimestre da gravidez, duas no segundo e três no terceiro), sendo ideal que a primeira consulta aconteça no primeiro trimestre e que, até a $34^{\mathrm{a}}$ semana, sejam realizadas consultas mensais. $\mathrm{O}$ indicado são que as consultas sejam realizadas a cada duas semanas entre a $34^{\mathrm{a}}$ e $38^{\mathrm{a}}$ semanas, e a partir da $38^{\mathrm{a}}$ semana as consultas devem ser semanais até o parto. (Brasil,2019).

É muito importante que as gestantes aproveitem o momento da consulta para colocar suas dúvidas, preocupações, experiências a fim de melhorar o diálogo com os profissionais de saúde. Nesta primeira consulta a gestante passará pela anamnese, exame físico e analise de exames laboratoriais.

Durante as próximas consultas o enfermeiro ou o médico costumam verificar o peso, a pressão sanguínea, sinais de inchaço das pernas e pés, a altura uterina, os batimentos cardíacos fetais e observam as mamas além de ensinar o que se pode 
fazer para prepará-las para a amamentação. O médico também avalia se a gestação é de baixo ou alto risco, a partir de avaliações de presença de doenças cardíacas, autoimune, insuficiência renal, alterações neurológicas, diabetes, desnutrição entre outras. É essencial questionar a gestante sobre os incômodos que ela vem sentindo, como azia, queimação, fraqueza, corrimento vaginal, hemorroidas, varizes, pois é a partir desta avaliação que o médico poderá indicar algumas medidas para diminuir as dificuldades e promover a saúde da mulher e do bebê.

\subsection{Vacinas e exames}

A gestante necessita realizar alguns exames durante o acompanhamento do pré-natal e atualizar o seu cartão de vacina para um desenvolvimento saudável de seu bebê. A tipagem sanguínea, por exemplo, serve para identificar o tipo de sangue da mãe. O hemograma identifica problemas como a anemia, que é muito comum na gravidez, já a glicemia mede a quantidade de açúcar na corrente sanguínea. Exames de urina, urocultura e preventivo de câncer de colo de útero também são de grande importância realizar. Alguns testes são feitos na atenção básica, como por exemplo: teste de sífilis, HIV, hepatite B, entre outros.

Assim como os exames as vacinações tem um papel fundamental para garantir um pré-natal seguro e também são de grande importância tanto para a gestante, quanto para o bebê. A vacina antitetânica (dT) imuniza tanto a mãe como o feto, já a vacina dTpa protege contra o tétano, difteria e coqueluche e deve ser tomada entre a $27^{\mathrm{a}}$ e a $36^{\mathrm{a}}$ semana. A vacina contra hepatite B só será realizada caso a mãe não esteja imunizada, neste caso ela deverá tomar três doses. Já a vacina contra influenza é recomendada que a gestante tome durante a gestação e após o parto. (Brasil,2018).

Já algumas vacinas devem ser evitadas durante a gestação, por exemplo, a Tríplice Viral, ela pode causar reações adversas e complicações com o bebê, ela só pode ser aplicada no pós-parto e no período de amamentação. Durante os primeiros meses de vida do bebê, sua imunização depende diretamente da mãe, os anticorpos da mãe são transmitidos para o feto durante a gestação e depois do seu nascimento continuam sendo repassados através da amamentação. Por isso a vacinação é essencial, pois protege tanto a mãe como o bebê.

\subsection{Pré-natal masculino}

O pré-natal do homem também visa promover o acesso do público masculino aos serviços de saúde, de maneira a ser utilizado como uma porta de entrada do homem na rede de atenção à saúde, pois esta precisa se cuidar para conseguir cuidar da sua família. Por isso é importante incluir, estimular a figura paterna a participar, acompanhar o pré-natal, frequentar os equipamentos de saúde de forma preventiva e desmistificar a paradigma que a atenção pré-natal é voltada somente para o público feminino. O pré-natal masculino também tem como reflexo a redução da violência doméstica e casos de sífilis congênita. (Lima, et al. 2018).

Além disso o pré-natal masculino visa não apenas na integração do homem, mas também uma oportunidade de inserir o homem nas ações voltadas para o cuidado de sua própria saúde, como por exemplo, práticas de atividades físicas, alimentação balanceada, redução no consumo de bebidas e deixar de fumar. (Vitoretti, et al. 2021).

Ao realizar os exames durante a gestação do filho, o homem fica mais ciente sobre a importância de manter sua saúde em dias, se torna mais participativo e mais tolerante com sua parceira durante esse momento tão especial na vida do casal. (Passos \& Rocha, 2013). 


\subsection{Importância do pai}

Segundo o ministério da saúde (Brasil,2018). Na caderneta da gestante o pré-natal do parceiro tem como principal objetivo preparar o pai para a paternidade, o cuidado com a sua saúde e também em atividades educacionais.

De acordo com um estudo científico a gravidez é um momento único, e cheio de diversas mudanças na vida da mulher, como mudanças emocionais e físicas também, com a presença do pai para ele entender que essa mudança é normal, é importante que o mesmo acompanhe a gestante na unidade de saúde durante a gestação, para uma gestação tranquila e segura. (Silva, et al. 2020).

O envolvimento paterno na gestação vai além de ser o provedor dentro de casa, e compreende com a sua participação direta com a gestante, e o apoio emocionalmente com a mulher, para a chegada de uma criança. (Santos, et al. 2020).

Umas das maiores justificativa da gestante sobre a ausência do parceiro nas consultas de pré-natal, é a cargo horaria de trabalho do parceiro, pois o mesmo é o único que trabalha em sua casa, ou, a mesma é mãe solteira e não tem nenhum vínculo familiar com seu parceiro, e a grande maioria não dão muita importância para a gestação, é ali que começa o vínculo familiar de pai e filho, e as consultas de pré-natal também servem para cuidar da saúde do homem de forma que ele entenda que sua saúde é de suma importância, fora o preparamento psicológico para a chegada de um criança, e o apoio do pai na hora do parto serve para passar mais segurança para a gestante e seus familiares.

Para o cuidado com a saúde do homem são feitos alguns testes como de HIV, Sífilis e Hepatite B, para que tenha a certeza que o pai não tem nenhuma doença sexualmente transmissível, e que passe mais segurança para a mãe durante a gestação, e que a criança nasça com mais saúde, esse teste e outros também são feitos na mãe para identificar alguma doença e iniciar o tratamento da mesma para que não possa afetar a criança.

De acordo com Borel, (2021). O estudo evidenciou que o envolvimento do pai compreende diversos aspectos, como o emocional e afetividade, é a uma das grandes responsabilidades que o profissional da saúde consiga introduzir a figura paterna no pré-natal.

Algumas mudanças acomete os pais durante a gravidez de suas parceiras, aonde o pai pode desenvolver alguns sintomas de couvade, apresentando sintomas físicos ou psicológicos semelhantes aos das mulheres. (Piccinin, et al. 2004).

Estudos mostram que desde o final do século passado o homem vem deixando de lado o comportamento rígido, e passando a assumir posições que até então eram destinadas as mulheres. Isso faz com que se altere também o conceito de paternidade, pois o pai participativo que cuida e zela dos filhos e divide com a mulher as preocupações da gestação vem sendo cada vez mais cobrado pela sociedade atual. (Ábdon, et al. 2017).

\subsection{A dificuldade do pai de acompanhar o pré-natal}

Segundo o estudo de Pompermaier e Freitas (2020), uma das maiores dificuldades do pai para acompanhar o pré-natal é que as consultas são em horários de expediente, e muitos alegam que não podem se ausentar do seu expediente de trabalho e tem ainda aqueles que desconhecem a importância desse momento tão especial.

Um dos motivos para ausência da figura paterna no pré-natal é falta de conhecimento da lei trabalhista, que relata que o pai pode deixar de comparecer o serviço sem prejuízo ao salário, até dois dias para acompanhar a consulta ou fazer alguns exames do círculo gravídico de sua esposa ou companheira. (Brasil,1943).

De acordo com Brito et al. (2013), as dificuldades mais recorrentes além das citadas acimas são, oscilações de humor da gestante, mudanças na vida conjugal/sexual, dificuldades financeiras, acesso da gestante ao serviço de saúde, e a realização de alguns exames laboratoriais.

A necessidade de conscientizar a figura paterna do dever e dos seus direitos á sua participação no planejamento reprodutivo deve ser feita pelos profissionais da saúde. A paternidade não deve ser vista apenas de um ponto de vista da obrigação 
legal, mas, sobretudo, como seu direito a participação de todos os processos, bem como acompanhamento da gravidez, do parto, do pós-parto e da educação da criança. (Brasil, 2008).

\subsection{Parto}

Dias antes do parto é normal que saia da vagina da mulher um muco grosso amarelado, com rajas de sangue, este é um sinal de que o parto se aproxima. A mulher sentirá sua barriga endurecer e leves contrações, o ideal é que ela não vá direto para o hospital, tome um banho, repouse e comece a observar o intervalo e a duração das contrações. Em geral o trabalho de parto dura de 8 a 12 horas, mas varia de cada gestante. (Brasil, 2018).

$\mathrm{O}$ ato fisiológico de parir passou a ser visto como patológico com o passar dos anos, fazendo com que cada vez mais o estimulo e o apoio que vivencia a mulher seja modificado. É claro que o avanço da tecnologia traz muitas melhorias a saúde obstétrica, no entanto o aumento das cesáreas, que seria um procedimento realizado só em casos específicos, se tornou um procedimento "comum", além de se utilizar medicações excessivas em um processo que é natural e fisiológico. Sem falar que o avanço da tecnologia aumentou o índice de parto operatório, morbimortalidade materna e neonatal, abortos clandestinos, esterilização em massa entre outros.

Para resgatar o parto natural, a Organização Mundial da Saúde e outros órgãos tem proposto algumas mudanças, como por exemplo, o incentivo a atuação da enfermeira obstetra na gestação e no parto, fazendo com que a mulher se enxergue como protagonista e se sinta respeitada. A participação da família durante toda essa fase também é de grande importância. O termo Humanização foi escolhido pelo Ministro da Saúde e sua equipe, para que o atendimento feito pelos profissionais da saúde não seja somente para aquilo que é visto ou palpado, mas também pelo que é falado pela gestante, assim pode-se entender melhor como ela está se sentindo e consequentemente ter resultados positivos no final da gestação. Castro, J. C. Clapis, M. J. (2005).

\subsubsection{Parto cesáreo}

De acordo com o estudo feito por Zimmermmann et al. (2018), a cesariana é descrita como o nascimento de um feto mediante a uma incisão abdominal e uterina, e quando a cesariana é indicada corretamente ela pode salva vidas, porém a um alto risco de infecção quando se compara ao parto normal.

E depois de aproximadamente 39 semanas, chega o tão sonhado momento da gestante, o parto. A cesárea é um procedimento cirúrgico desenvolvido para ser realizado quando existe complicações no parto. No entanto, existe um grande índice de cesárias no Brasil, um estudo feito pela Fundação Oswaldo Cruz aponta que cerca de 75\% das mulheres não querem o parto cesárea por conta da recuperação difícil e demorada. No entanto, a análise feita em duas maternidades do município do Rio de Janeiro mostra que quanto maior o tempo entre a admissão no hospital e o parto, mais frequente é essa solicitação. Ou seja, a maioria das mulheres prefere o parto natural, porém, por conta das circunstancias da assistência entre o pré-parto elas acabam escolhendo a cesárea. (Barbosa, et al. 2004).

\section{Considerações Finais}

O estudo evidenciou que a presença da figura paterna é de grande importância durante as consultas de pré-natal, portanto a enfermagem tem o papel fundamental de orientar e incluir o pai da melhor forma possível durante todo o pré-natal de sua parceira.

Sabemos que a inclusão do pai no pré-natal é aonde ele vai poder compreender todas as mudanças que ocorrerá no corpo de sua parceira tanto naturais como psicológicas, e os profissionais da saúde poderá prestar cuidados para saúde do homem, também é aonde começa o primeiro vínculo familiar de pai e filho, e, aumenta o vínculo afetivo entre os parceiros. 
Este trabalho tem como intuito fazer que a presença dos pais sejam mais frequentes durante todas as consultas de prénatal, que o seu apoio é fundamental e também para prestar um cuidado a saúde do homem durante todo o ciclo gestacional.

Ainda como sugestão, a melhoria das Políticas de saúde e programas que são voltados para esses clientes. Pois sabemos que sua participação é fundamental em todo o período gestacional.

E tudo isso pode ser conciliado, e é aí que entra a equipe de enfermagem, o profissional tem como função conversar e informar sobre os direitos que o pai tem de comparecer nas consultas, se ele não conhecer os seus direitos não poderão reivindicalos. Nós como profissionais devemos sempre dar aos nossos clientes as informações necessárias para que eles compreendam o quanto a sua participação é importante para mãe e para o bebê, mas principalmente para ele mesmo, pois é um momento único que a família irá vivenciar, e mesmo que venham outras gestações, cada uma tem o seu valor.

\section{Referências}

Ábdon, L. C. et al. (2017). A visão das gestantes acerca participação do homem no processo gestacional. Revista de enfermagem do centro-oeste mineiro, 7.

Barbosa, G. P. et al. (2003). Parto cesáreo: quem o deseja? em quais circunstâncias. saúde pública,19.

Borel, E. M. et al. (2021). Percepção das gestantes acerca da participação e envolvimento do parceiro/pai na gestação. Revista eletrônica acervo saúde, 13. Brasil. (1943). Previdência da república casa civil. Brasília.

Brasil. (2008). Política nacional de atenção integral à saúde do homem. Ministério da saúde.

Brasil. (2016). lei no 13.257, de 8 de março de 2016. Diário Oficial da União. Brasília.

Brasil. (2018). Caderneta da gestante. Ministério da saúde. Brasília.

Brasil. (2019). Pré-natal. Ministério da saúde. Brasília.

Brito, R. S. et al. (2013). Dificuldades vivenciadas pelo homem durante a gravidez da companheira. Rev Rene, 14.

Camargos, L. F. et al. (2021). Avaliação da qualidade dos registros de cartões de pré-natal de mulheres urbanas. Escola anna nery, 25.

Castro, J. C., \& Clapis, M. J. (2005). Parto humanizado na percepção das enfermeiras obstétricas envolvidas com a assistência ao parto. latino-am enfermagem, 13.

Lima, M. B. L. et al. (2018). a importância da realização do pré-natal e pré-natal masculino. Congresso brasileiro de enfermagem obstétrica e neonatal, 1.

Passos, N., \& Rocha, C. (2013). Pré-natal masculino: concepções do enfermeiro (a) sobre a importância na saúde do homem. Faculdade Maria Milza, 1.

Piccinin, C. A. et al. (2004). O envolvimento paterno durante a gestação. Psicologia reflexão e critica, 17.

Pompermaier, C., \& Freitas, G. T. (2020). A participação paterna no pré-natal. Revista área das ciências da vida e saúde - artigos, 5.

Santos, E. M. R. et al. (2020). Participação do pai no acompanhamento durante o pré-natal: revisão integrativa de literatura. Centro universitário cesmac.

Silva, L. S. et al. (2015). Análise das mudanças fisiológicas durante a gestação: desvendando mitos. Faculdade montes belos, 8.

Silva, S. S. B. et al. (2020). A importância da participação do pai no acompanhamento do pré-natal. Faculdade são Paulo-fsp, 13.

Vitoretti, F. M. et al. (2021). O pré-natal do parceiro sexual: importância para a saúde do homem e da gestante. Revista Eletrônica Acervo Saúde, 13.

Zimmermmann, J. B. et al. (2018). Infecção em cicatriz de cesariana. Faculdade de ciências médicas de Sorocaba, 20. 